\title{
Pseudo prune belly syndrome
}

\author{
*Devdeep Mukherjee ${ }^{1}$, Joydeep Das ${ }^{2}$, Prabal Niyogi ${ }^{3}$, Ritabrata Kundu ${ }^{4}$
}

Sri Lanka Journal of Child Health, 2017; 46(4): 375-376

DOI: http://dx.doi.org/10.4038/sljch.v46i4.8388

(Key words: Prune belly syndrome, urinary tract abnormality, cryptorchidism, abdominal wall defect)

\section{Case report}

A 2.5 month old male infant was admitted with a history of fever for 5 days. He had bilateral cryptorchidism with palpable right kidney. The abdominal wall was normal (Figure 1). There was no other systemic abnormality. Antenatal scan was not performed.

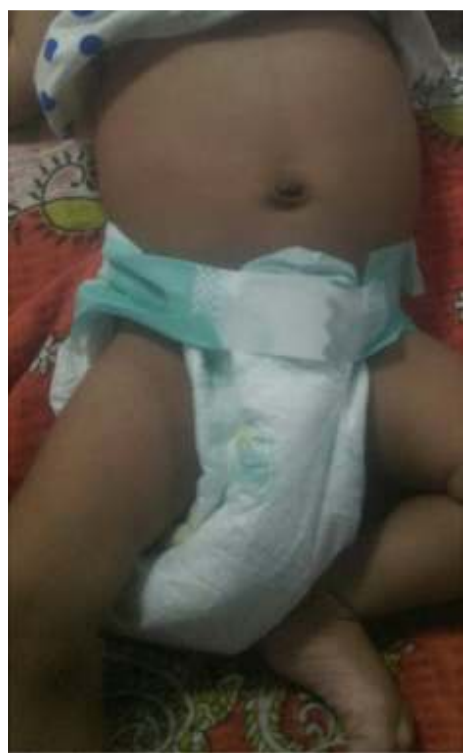

Figure 1: Normal abdominal wall

The haemoglobin level was $10 \mathrm{~g} / \mathrm{dl}$ and the total leucocyte count $31,400 / \mathrm{cu} \mathrm{mm}$ (neutrophils $58 \%$, lymphocytes $38 \%$ ). C-reactive protein was 25.2 $\mathrm{mg} / \mathrm{L}$, blood urea $50 \mathrm{mg} / \mathrm{dl}$, the serum creatinine $0.52 \mathrm{mg} / \mathrm{dl}$ with normal serum electrolytes and normal liver function. Urine had plenty of pus cells per high power field and urine culture revealed growth of E.coli which was sensitive to carbapenems, amikacin, nitrofurantoin and

${ }^{1}$ Senior Resident, ${ }^{2}$ Assistant Professor, ${ }^{3}$ Deputy Director, ${ }^{4}$ Professor, Institute of Child Health, Kolkata, India

*Correspondence: devdeep_dm@rediffmail.com (Received on 08 June 2016: Accepted after revision on 15 July 2016)

The authors declare that there are no conflicts of interest

Personal funding was used for the project.

Open Access Article published under the Creative

Commons Attribution CC-BY (c) (P) License cotrimoxazole. Magnetic resonance imaging (MRI) of kidney-ureter-bladder showed enlarged right kidney with hydronephroureterosis with grade IV vesico-ureteric reflux (VUR) and multi cystic dysplastic kidney with almost absent renal parenchyma on left side. The right ureter was dilated and tortuous and the left ureter was not visualised (Figure 1).

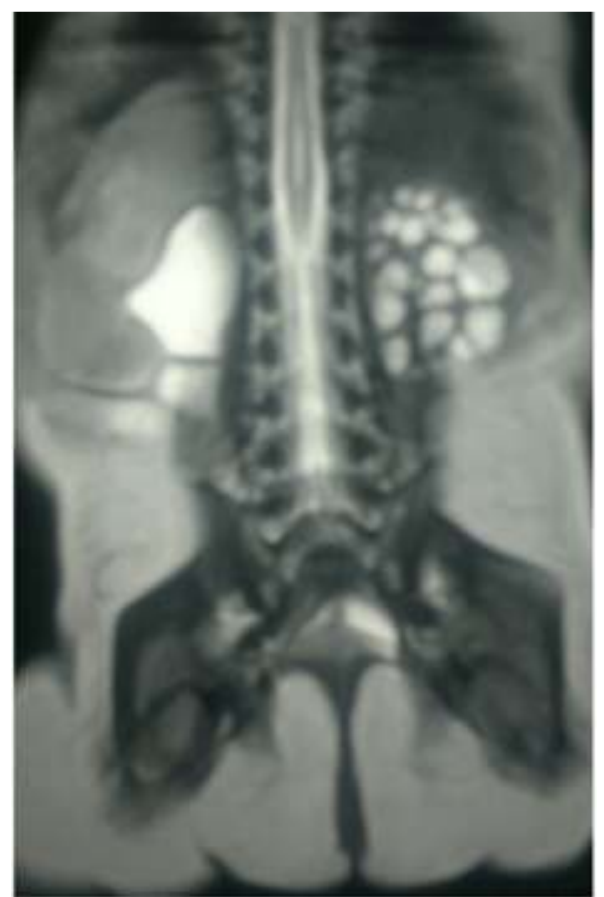

Figure 2: MRI abdomen showing enlarged right kidney with hydronephroureterosis

Renal scintigraphy showed a functionality of $63.84 \%$ in the right kidney and $16.76 \%$ in the left kidney. Ultrasonography located the right testis within the inguinal canal, but the left was not visible. The presence of renal abnormalities leading to urinary tract infection (UTI) with cryptorchidism in an infant with normal abdominal wall confirmed the diagnosis of Pseudo Prune Belly syndrome (PPBS). He was treated with Meropenem and is presently in follow up with monitoring of blood pressure and renal function. Orchidopexy has been planned.

\section{Discussion}

Prune Belly Syndrome (PBS) is characterised by complete or partial abdominal wall deficiency, bilateral cryptorchidism and urinary tract 
abnormality. The incidence varies between one in 35,000 to one in 50,000 with greater predominance in males ${ }^{1,2}$. Mutation is usually sporadic although familial forms are seen ${ }^{3}$. It possibly occurs due to an aberration in mesenchymal development that combines to produce abdominal, urologic and testicular abnormalities. The paraxial mesoderm may be less affected causing sparing of the abdominal wall ${ }^{4}$. PPBS refers to those where one of the triad are absent. Our index case had normal abdominal wall. Urinary tract abnormalities were detected following imaging, similar to the study by Lebowitz and Griscom ${ }^{5}$. Diagnosis is often delayed because of normal appearance of abdominal wall in PPBS $^{5}$. Prognostication is determined by urinary tract abnormalities and renal function.

\section{References}

1. Sutherland RS, Mevorach RA, Kogan BA. Urological review. The prune-belly syndrome: Current insights. Pediatric Nephrology 1995; 9: 770-8.

https://doi.org/10.1007/BF00868740

PMid: 8747124
2. Woodhouse CR, Ransley PG, InnesWilliams D. Prune Belly Syndrome-Report of 47 Cases; Archives of Disease in Childhood 1982; 57: 856-9.

https://doi.org/10.1136/adc.57.11.856

PMid: 6128960 PMCid: PMC1628035

3. Ramasamy R, Haviland M, Woodard JR, Barone JG. Patterns of inheritance in familial Prune Belly syndrome; Urology 2005; 65: 1227-8.

PMid: 15922438

4. Greskovich FJ III. Nybeng LM Jr; The prune belly syndrome: a review of its aetiology, defects, treatment and prognosis. Journal of Urology 1988; 140: 707-12. https://doi.org/10.1016/S00225347(17)417 93-9

5. Lebowitz RL, Griscom NT. Neonatal hydronephrosis: 146 cases; Radiological Clinics of North America 1977;15:49-59 PMid: 139634 